\section{Mental health and ethnicity: an Irish dimension}

\author{
PATRICK J. BRACKEN, LIAM GREENSLADE, BARNEY GRIFFIN and \\ MARCELINO SMYTH
}

The importance of issues such as ethnicity, culture and racism in relation to mental health is now well established and generally accepted in psychiatry. However, the debate around these issues in Britain has been limited by an almost exclusive identification of ethnicity with skin colour. In most research ethnic minority groups are compared, by and large, with a 'White' group which is assumed to be homogeneous, particularly with regard to issues of culture and the experience of social disadvantage and racism. There is now considerable evidence that of all the ethnic minorities in Britain, the Irish have the poorest record of both physical and mental health (Cochrane \& Bal 1989; Pearson et al, 1991; Greenslade, 1994). In spite of this, little research has been focused on the health needs of this community.

\section{IRISH PEOPLE IN BRITAIN}

This lack of research interest is particularly anomalous given the size of the Irish community in Britain. Irish-born people make up approximately $1.5 \%$ of Britain's population, and when people of Irish parentage are included, the size of the community rises to 2.5 million, that is, $4.6 \%$ of the population (Hickman \& Walter, 1997), making Irish people in Britain the largest migrant minority in Western Europe.

The mortality rates of Irish-born people exceed those of all residents of England and Wales by approximately $30 \%$ for men and $20 \%$ for women (Haskey, 1996). Irish men are the only migrant group whose life expectancy worsens on emigration to England (Pearson et al, 1991). In a recent study (Harding \& Balarajan, 1996) it was shown that these excessive mortality rates persist into the British-born children of Irish migrants, a finding which is very unusual in migrant mortality research (Haskey, 1996).

\section{MENTAL HEALTH OF IRISH PEOPLE IN BRITAIN}

Evidence that the Irish are grossly overrepresented as users of psychiatric services has been available for a number of years. In both the 1971 and 1981 Mental Health Enquiries (see Table 1; Cochrane, 1977; Cochrane \& Bal, 1989) Irish people in Britain had the highest rates of mental hospitalisation and were more than twice as likely as the native-born to be hospitalised for some forms of psychological distress
I. Schizophrenia and paranoia.

2. Affective psychoses and depressive disorders.

3. Includes neurotic depression. (see Table 2). Irish people were overrepresented in most diagnostic categories but the figures for depression and alcoholrelated disorders were particularly striking. Men and women born in the Republic of Ireland had rates of admission for depression approximately two and a half times those of their native-born counterparts. For alcohol-related disorders, men born in the Republic of Ireland suffered approximately nine times, and women seven times, the rate of English-born people. The figures for people born in Northern Ireland were somewhat less than those of the Republic, but are considerably higher than English rates (Cochrane \& Bal, 1989). Irish rates of schizophrenia were second only to those of the African-Caribbean population. However, the overall hospitalisation rate for Irish people was far higher than for the African-Caribbean group, relatively a more researched population in the field of ethnicity and mental health.

The Irish-born population in Britain is an ageing one, with over $26 \%$ of its

Table 1 Age-standardised mental hospital admission rates for all diagnoses by selected nativity groups in England and Wales (197I) and England (1981). Rates per 100000 population (data from Cochrane \& Bal, 1989)

\begin{tabular}{lccccc}
\hline Country of birth & & 1971 & & \multicolumn{1}{c}{1981} \\
\cline { 2 - 3 } \cline { 5 - 6 } & Males & Females & & Males & Females \\
\hline Irish Republic & 1065 & 1153 & & 1054 & 1102 \\
Northern Ireland & 1391 & 102 & & 793 & 880 \\
England & 434 & 551 & 418 & 583 \\
\hline
\end{tabular}

Table 2 Rates of mental hospital admissions for selected nativity groups in England (1981) per 100000 population by gender and diagnosis (data from Cochrane \& Bal, 1989)

\begin{tabular}{|c|c|c|c|c|c|}
\hline \multirow[t]{3}{*}{ Diagnosis } & \multicolumn{5}{|c|}{ Country of birth } \\
\hline & \multicolumn{2}{|c|}{ Irish Republic } & \multicolumn{3}{|c|}{ England } \\
\hline & Male & Female & Male & Female & \\
\hline Schizophrenia' & 158 & 174 & 61 & 58 & \\
\hline Other psychoses & 36 & 50 & 16 & 27 & \\
\hline Depression ${ }^{2}$ & 197 & 410 & 79 & 166 & . \\
\hline Neuroses ${ }^{3}$ & 62 & III & 28 & 56 & \\
\hline Personality disorder & 62 & 80 & 30 & 35 & \\
\hline Alcohol misuse ${ }^{4}$ & 332 & 133 & 38 & 18 & \\
\hline Drug misuse & 13 & 8 & 5 & 3 & \\
\hline
\end{tabular}

4. Alcohol psychosis and alcohol dependence and non-dependent use of alcohol. 
members above pensionable age (Greenslade, 1993). In view of the fact that up to $15 \%$ of elderly people suffer depressive illness, it is likely that the over-representation of Irish people in mental hospitals will continue for the foreseeable future.

Admission rates for various diagnostic categories are influenced by a number of factors and cannot be taken to reflect directly the level of psychiatric morbidity in any particular population. A number of theories have been offered to explain the low rates of admission for Asian people in Britain. For example, it has been suggested that Asian general practitioners may think it inappropriate to refer people with psychiatric symptoms to hospital (Ineichen, 1990). In relation to the observed higher rates of hospitalisation of African-Caribbean people with a diagnosis of schizophrenia, a number of problematic issues have been identified. Most important of these are numerator problems of case definition and case identification. However, issues of diagnostic accuracy do not arise when admission figures alone are being examined. It would be difficult to explain the marked difference between the Irish admission rates and those of the native-born simply on the basis of numerator inaccuracy. Likewise, it is widely accepted that census data relating to Irish people in England and Wales are unreliable. It is likely that the census figures for the size of the Irish population represent an under-estimation (Hickman \& Walter, 1997). However, the true size of the Irish population would have to be double the census figure if this denominator question were to account for the excess of Irish admissions.

Some commentators have pointed to the fact that high mental hospital admission rates have also been recorded in parts of Ireland itself and in Irish immigrants to North America. This has been used to explain the excess of Irish people admitted in Britain, particularly with a diagnosis of schizophrenia, the assumption being that all excess admission rates reflect an actual increased prevalence of schizophrenia in Irish people (Cochrane \& Bal, 1987). However, in a World Health Organization study in which identical case-finding and diagnostic techniques were used in 12 centres worldwide it was found that the incidence of schizophrenia in Dublin, Ireland, was in the mid-range of all the countries studied (Sartorius et al, 1986) and in a recent study in the west of Ireland the lifetime prevalence rate for schizophrenia was not in excess of rates found elsewhere (Kendler et al, 1993).

In a series of reports, published in the 1980s, the Irish Health Research Board has presented strong evidence for a social explanation for high admission and readmission rates in Ireland. A number of factors have been identified as important:

"a relatively large provision of psychiatric hospital beds. few outpatient services (especially in rural areas), rural poverty, unemployment, isolation and a large percentage of elderly men and women" (Cabot. 1990)

If these features of Irish society are important in promoting high hospitalisation rates, one could reasonably expect to find lower rates after emigration to a more affluent country. This does not appear to happen in Britain. It appears that whichever way one examines the data pertaining to mental illness and Irish people in England and Wales, one has to conclude that there is a real problem and that there are real issues to be faced. This is unlike the situation in North America where there has been conflicting evidence regarding the incidence and prevalence of mental illness among Irish people.

This excess of hospital admissions of Irish people in Britain has its material correlate in suicide, parasuicide and selfharm. For the period 1979-1983 excess mortality for suicide was 26 and $30 \%$ for Irish-born men and women, respectively (Raleigh \& Balarajan, 1992). Among younger age groups in the same period the excess was even greater. For Irish-born women aged $20-29$ the excess was $167 \%$ and for men $\mathbf{7 4 \%}$. Other studies have shown that Irish-born people are overrepresented in admission figures for attempted suicide and self-poisoning.

For the period 1988-1992 Irish people in Britain had an age-standardised mortality rate for suicide of 17.4 per 100000 . This was $53 \%$ in excess of the native-born rate (11.4 per 100000). Among second-generation Irish people, who are excluded from the mental hospital admission data, the excess due to suicide was $25 \%$ (Harding $\&$ Balarajan, 1996).

\section{SOCIAL SITUATION OF IRISH PEOPLE IN BRITAIN}

Like Asian and African-Caribbean immigrants to Britain, Irish people have come as migrant workers. Because of this, many experiences have been shared by these groups. For example, they have tended to settle in the major cities where they have traditionally found employment. In addition, Irish people share in the social disadvantages experienced by AfricanCaribbean and Asian immigrants. Irish people are twice as likely to be unemployed as native-born people $(16.7 \%$ compared with $8.6 \%$ for heads of household) and more likely to be involved in manual, unskilled and personal service employment (44.5\% compared with $28.2 \%$ British people; Greenslade et al, 1991). Many Irish men who migrated to Britain have been employed as unskilled workers. Many seek work in the building industry where employment is often erratic and conditions unhealthy. Such men often lead a nomadic existence, following work from one site to another, moving from one city to another, never putting down roots and gradually losing contact with families and communities back in Ireland. Poor housing and homelessness are problems particularly associated with Irish people in Britain. As O'Meachair (1988) has commented:

\footnotetext{
"In London, one-in-three occupants of hostels for the homeless in Inner London are Irish; onein-four in Outer London are Irish. In 1985. 38\% of casual users of DHSS resettlement units were Irish and two out of every seven people who sleep rough in central London are Irish."
}

The fact that Irish people were specifically excluded from the tightening-up process in the series of Nationality and Immigration Acts since the Second World War is often taken as evidence that there is now more tolerance and acceptance of the Irish compared with other immigrant groups. However, the study by Harding \& Balarajan (1996) indicates that high mortality rates continue in the second generation. Harding \& Balarajan (1996) argue that there is a need to explore cultural as well as socio-economic issues in relation to the health of the Irish in England and Wales. In particular they note that the conflict in Northern Ireland has made it very difficult for Irish people living in England and Wales to promote a "positive Irish identity".

In a recent report, prepared for the Commission on Racial Equality, considerable evidence was presented of strong antiIrish discrimination in many parts of British society (Hickman \& Walter, 1997). There is also evidence that with regard to the experience of racism there is much in common between the Irish community and the African-Caribbean and Asian 
communities. Within living memory, many immigrants to English cities were faced with signs such as "No Blacks or Irish" in the windows of rented accommodation. The tabloid press in Britain can sometimes be overtly racist in its reporting of the Irish community and Irish affairs.

\section{USE OF ETHNICITY CATEGORIES IN RESEARCH}

In recent years a number of prominent academics have begun to question the easy use of the categories White, Asian and African-Caribbean in health and social research. These categories, which carry a strong racial connotation, are simply inadequate to address the complex ethnic reality of modern Britain. In spite of this, all ethnic categorisations are, in the end, strategic devices, and it can be argued that the use of relatively crude categorisations can be helpful as a first step in demonstrating differential social and health experiences. However, once it becomes clear that such categorisations are in fact working to conceal such differential experiences, there is surely a compelling argument in favour of using more thoughtful approaches. Our argument is that the category 'White' requires substantial re-examination, both in terms of its usefulness in empirical research and also as a conceptual tool. It now behoves researchers working in different areas, including the field of mental health, to explain more clearly why they are using particular ethnic categories.

In the British mental health and ethnicity debate there has been a great deal of interest in two particular trends: the apparent higher rates of schizophrenia among both first- and second-generation AfricanCaribbean people and the lower rates of utilisation of psychiatric services by Asians. The neglect of an Irish dimension in this debate and the almost exclusive concern with these two trends is associated with a wider academic neglect of the Irish community in Britain.

The dominant paradigm for understanding ethnicity within the British dis-

PATRICK J. BRACKEN, MD, Department of Social and Economic Studies. University of Bradford; LIAM GREENSLADE, Liverpool Irish Centre, Mount Pleasant, Liverpool; BARNEY GRIFFIN, BPhil, Birmingham Irish Mental Health Forum, Ladywood. Birmingham: MARCELINO SMYTH, MRCPsych. Nor thern Birmingham Mental Health Trust. Birmingham

Correspondence: Patrick J. Bracken. Consultant Psychiatrist/Senior Research Fellow, Department of Social and Economic Studies. University of Bradford. Richmond Building. Bradford BD7 IDP

(First received II March 1997, final revision II September 1997, accepted II September 1997)

courses of transculturalism, race-relations and anti-racism has been in terms of a Black-White dichotomy. To a large extent these discourses have been developed as antitheses to earlier colonial frameworks which involved notions of racial superiority. The Irish, a native population which happened to be White, were always difficult to place within such frameworks. They constituted, by their existence as a colonised people, an affront to the very idea of the 'White man's burden', and thus challenged many of the fundamental assumptions of colonial discourse. As contemporary debates around ethnicity and racism tend to mirror these colonial debates, perhaps it is not surprising that postcolonial transculturalism has found the Irish problematic, and thus easier to ignore. Given the evidence presented here, the continued neglect of this community in Britain is now untenable. In particular, there is an urgent need for both quantitative and qualitative research relating to the mental health needs of Irish immigrants.

\section{REFERENCES}

Balarajan, R. (1995) Ethnicity and variations in the nation's health. Health Trends, 27, 114-119.

Cabot, M. R. (1990) The incidence and prevalence of schizophrenia in the Republic of Ireland. Social Psychiatry and Psychiatric Epidemiology, 25, 210-215.

Cochrane, R. (1997) Mental illness in immigrants to England and Wales: an analysis of mental hospital admissions. 1971. Social Psychiatry, 12. 25-35.

_ Bal, S. S. (1987) Migration and schizophrenia: an examination of five hypotheses. Social Psychiatry, 221. $|8|-19 \mid$.
- 2 (1989) Mental hospital admission rates of immigrants to England: a comparison of 1971 and 1981. Social Psychiotry and Psychiatric Epidemiology, 24. 2-11.

Greenslade, L. (1993) The Irish in Britain in the 1990's: A Preliminory Report on the 1991 Census. Census Reports No. I. Liverpool: Institute of Irish Studies.

- (1994) Caoinean an lon dubh: towards an Irish dimension in 'ethnic' health. Irish Studies Review, 8. 2-5.

_, Pearson, M. \& Madden, M. (1991) The Irish in Britain: Socio-Economic and Demographic Conditions. Occasional Papers in Irish Studies No 3. Liverpool: Institute of Irish Studies.

Harding, S. Balarajan, R. (1996) Patterns of mortality in second generation Irish living in England \& Wales: Iongitudinal study. British Medical Journal, 312. 1389-1392

Haskey, J. (1996) Mor tality among second generation Irish in England \& Wales. British Medical Journal, 312. 1373-1374.

Hickman, M. J. \& Walter, B. (1997) Discrimination and the Irish Community in Britoin. London: Commission for Racial Equality.

Ineichen, B. (1990) The mental health of Asians in Britain. British Medical Journal, 300. 1669-1670.

Kendler, K. S., McGuire., M., Gruenberg, A. N., et al (1993) The Roscommon Family Study, I: Methods. diagnosis of probands, and risk of schizophrenia in relatives. Archives of General Psychiatry, 50, 527-540.

O'Meachair, G. (1988) The Irish: Britain's forgotten Immigrants. Social Work Today, 19. $18-19$.

Pearson, M., Madden, M. \& Greenslade, L. (1991) Generations of an Invisible Minority. Institute of Irish Studies Occasional Paper No 2. Liverpool: Institute of Irish studies.

Raleigh, V. S. Balarajan (1992) Suicide levels and trends among immigrants in England and Wales. Health Trends. 24, $91-94$

Sartorius, N., Jablensky, A., Korten, A., et ol (1986) Early manifestations and first-contact incidents of schizophrenia in different cultures. Psychological Medicine, 16. 909-928. 